\title{
The role of ICTs in the transformation and the experience of travel
}

\author{
Martin E. H. Lee-Gosselin • Ron N. Buliung
}

Published online: 22 June 2012

(C) Springer Science+Business Media, LLC. 2012

It would be difficult to overstate the significance of the worldwide increase in access to information and communications technologies (ICTs) over the past 5 or 6 years. One-third of the global population is now on-line, and global penetration of mobile-cellular telephony had reached 5.9 billion subscriptions in 2011 (ITU 2011). This compares to a world population, over the age of 9, of 5.7 billion in the same year. Between 2006 and 2011, there was a doubling in the number of mobile-cellular broadband subscriptions, a type of higherorder service that supports mobile and rapid sharing of larger volumes of data (ITU 2011). With regard to growth in information infrastructure, Europe leads the world in terms of the supply of bandwidth, with an average per user of nearly 90,000 bits per second. The Americas (including Canada and the US) follow, yet clear global disparities persist. In Africa, for example, the average bandwidth per user is around 2,000 bits per second (ITU 2011).

The implications for transport systems of such a diffusion of ICTs are arguably profound. Initially, the role of ICTs was viewed primarily through the lens of improved traveller information. However, as was observed a decade ago by a US National Academies Advisory Board (STECRPAB 2002), the combination of ICTs with other fastevolving technologies, such as control and propulsion systems, and alternative fuels, provided the conditions for a veritable technological revolution in transportation. The expected outcome was a transformation, not just in the supply of cleaner and more fuelefficient motorised vehicles, but also in the human activity patterns that shape travel demand, resulting in major impacts on energy consumption, the environment and public health-although not necessarily always in a desirable direction. While it is not our purpose here to evaluate the extent to which these outcomes are occurring, we are persuaded

\footnotetext{
M. E. H. Lee-Gosselin ( $\square)$

ÉSAD-CRAD, Pavillon Félix-Antoine-Savard, Université Laval, 2325 rue des Bibliothèques,

Local 1612, Québec, QC G1V 0A6, Canada

e-mail: Martin.Lee-Gosselin@CRAD.ulaval.ca

R. N. Buliung

Department of Geography, University of Toronto Mississauga, 3359 Mississauga Road,

Mississauga, ON L5L 1C6, Canada

e-mail: ron.buliung@utoronto.ca
} 
that research to understand the rapidly evolving role of ICTs in both the transformation and the experience of activities and mobility is of considerable importance to the design of appropriate transport policy.

In particular, we are conscious that the rapidly increasing diffusion of ICTs has created the conditions for many "natural experiments" during the first decade of the 21st century. The opportunity to study the relationship between travel and ICTs when their development and diffusion was in its early mass-market stages has gone forever: yet it is under such circumstances that we had the best opportunity to sort out the behavioural mechanisms involved. These were the motivations to bring together this collection of papers and, with Martin Dijst of Utrecht University and Marius Thériault of Université Laval, to organise an international colloquium ${ }^{1}$ at which early versions of the papers were presented.

The four papers in this special issue report on research conducted in 2002-2004, 2007 (two papers) and 2008. They contributed to two key transport themes of the Québec colloquium: ICTs and the mutation of everyday activity and mobility patterns; and ICTs, work and the multiplexing of activities during travel. Other papers, published elsewhere, focused on ICTs, social networks, and constructs of space/time, and on cybershopping. Collectively, these themes are quite representative of a lively body of recent research in higher-income countries to explore the relationship between ICTs and travel behaviour. However, the colloquium organisers regretted that similar work in lower-income countries was not on the programme. All four studies published here were conducted in Northern countries that have an advanced supply of higher order infrastructures, both for moving information on-line via mobile or fixed Internet, and for moving people across space, using modern transport systems. Nevertheless, within the territories studied, there remain urbanto-rural and quite significant neighbourhood-to-neighbourhood disparities in service provision and access.

Further, when we look across the papers, we observe important national differences in context. The papers by Buliung et al. and Miranda-Moreno et al., which were set in the Canadian provinces of Ontario and Quebec, describe travel processes that occur where there are much higher levels of personal vehicle use than is the case in the Netherlands and Norway, the settings for the other two papers by Alexander and Dijst, and Gripsrud and Hjorthol. With regard to info-mobility, the opportunity for individual engagement with fixed (wired) broadband appears to be higher in Netherlands and Norway than in the Canadian context. According to data from the OECD (2012), among 34 OECD nations, per-capita fixed broadband subscriptions are highest in the Netherlands $(38.5 / 100$ inhabitants). Norway was ranked fifth (34.9 per 100 inhabitants), while Canada ranked thirteenth (31.2/100 inhabitants - these OECD data are not available at the provincial level). With regard to mobile wireless broadband subscriptions of any kind, Norway was again in fifth place with 76.4/100 inhabitants), the Netherlands was 18th with $44.1 / 100$ inhabitants, and Canada was again lower with 31.8/100 inhabitants, putting it in 26th place. Perhaps more importantly, in dedicated mobile data subscriptions-a service category that likely correlates with work activity while moving-Norway was in eighth place with 22.8 subscriptions per 100 inhabitants, well ahead of the Netherlands in 16th place with 11.2 per 100 inhabitants, and Canada in 23rd place with only 3.3/100 inhabitants.

As is normal in emerging fields of research, each of these four papers in its own way illustrates the importance of broadening conceptual frameworks for data collection and

\footnotetext{
${ }_{1}$ Fourth specialist meeting of the network ICT: mobilizing persons, places and spaces, Sainte-Pétronille, Île d'Orléans, Québec, Canada, 7-9 Oct 2009.
} 
analysis. For example, after observing much heterogeneity in ICT use within conventional professional groups, Alexander and Dijst undertook a rigorous clustering of professionals that took account of spatial and temporal work practices: it emerged in the context of the Netherlands that it was important for understanding the role of ICTs to distinguish carbased telecommuters from telecommuters who depended upon public transport, while those whose work was strongly fragmented in time comprised a group of their own. In Norway, Gripsrud and Hjorthol studied ICT-aided work that took place during regional and longer-distance rail journeys. They concluded that they could make better sense of travellers' evaluations of the productivity of that work by observing the role of working conditions on board, and the surprisingly frequent recognition by employers of travel time so used, and not just which ICTs the travellers had available. In the rapidly growing region of Toronto, Canada, Buliung et al. showed that a quite sophisticated ICT system to match travellers with similar commuting needs was rarely adequate to incite the launch of a new car pool. They demonstrated that this could best be addressed by exploring the relationship of the ICT system to a broader set of supportive workplace policies, and by letting go stereotypical expectations about travel behaviour, such as the idea that carpool matches can not work for travellers with odd working hours-something that other parts of their results showed to be positively related to carpool formation. For their part, in Quebec City, Miranda-Moreno et al. followed up their strong suspicion that the relationships between available ICTs and the amount of travel resulting from the spatial dispersion of activities could not be properly analysed unless the statistical model used allows for unobserved factors that influence both the choices to use ICTs, and travel outcomes. Their results, from a time when ICT penetration was in the $40-70 \%$ range, suggest that the effects of ICTs can be underestimated by as much as an order of magnitude or more, and may even have the wrong sign, if such endogeneity is ignored.

The above are just some examples of how these papers make the case for more comprehensiveness in the frameworks that guide this area of research. A common thread of great importance is the growing acceptance by travel behaviour researchers that interactions via ICTs are part of their remit, and that these interactions overlap travel and activity, as we have conventionally defined them. Efforts of the past decade to observe choice dynamics, notably the spatio-temporal planning of personal and household activities, are certainly relevant to understanding the effects of ICTs, be they enabling or disruptive. Of course some ICTs, such as highly portable mobility-aware devices, are also making innovative and valuable contributions to the observational toolkit.

The challenge is to adapt our research methods quickly enough to face such rapid changes in technology, and the human response to them in different contexts. Precisely how national differences, noted above, in the take-up of different ICTs are expressed at the scale of the sub-region, city or metropolis, is partly reflected in the research reported in this special issue. In the presence of data describing an uneven geography of participation in the information economy, these papers begin to contribute to a growing body of work on the differences and commonalities in how activities, travel and mobility (in all its forms) are being transformed and experienced as new ICTs spread around the globe.

Acknowledgments The guest editors gratefully acknowledge the financial support for this stream of work from: the Social Sciences and Humanities Research Council of Canada grant: "Wired Cities" (University of Toronto Mississauga), the Fonds québécois de recherche sur la société et la culture (FQRSC) grant: "Accès à la Cité" (Université Laval), and the network Villes Régions Monde, sponsored by FQRSC. 


\section{References}

International Telecommunication Union: The world in 2011: ICT facts and figures. www.itu.int/ITU-D/ ict/facts/2011/material/ICTFactsFigures2011.pdf (2011). Accessed 11 May 2012

Organization for Economic Cooperation and Development: Fixed and wireless broadband subscriptions per 100 inhabitants. http://www.oecd.org/document/54/0,3746,en_2649_37441_38690102_1_1_1_374 41,00.html (2012). Accessed 11 May 2012

STECRPAB: Surface transportation environmental cooperative research program advisory board. Transportation Research Board Special Report 268, Washington D.C. (2002)

\section{Author Biographies}

Martin E. H. Lee-Gosselin is Emeritus Professor in the Graduate School of Planning at Université Laval, Quebec City. He specialises in survey and analysis methods to investigate activity/travel behaviour both as it exists now, and in response to future changes in policy or the availability of alternative fuel, vehicle and telecommunications technologies.

Ron N. Buliung is Associate Professor of Transport Geography and Spatial Analysis at the University of Toronto Mississauga, and Research Associate, UofT Cities Centre. He received his Ph.D. in Geography at McMaster University in 2004. His research interests broadly cover the relationship between the technologies of mobility (ICTs, transport), travel behaviour, and the development of cities and regions. 